\title{
Grystal growth rates in polar firn
}

\author{
Hitoshi Shoji, ${ }^{*}$ Atau Mitani, Kohji Horita, \\ Snow and Ice Laboratory, Department of Earth Sciences, Toyama University, Toyama 930, Japan \\ Chester C. Langway, JR \\ Ice Core Laboratory, State University of New York at Buffalo, Buffalo, NY 14226, U.S.A.
}

\begin{abstract}
Continuous crystal-size measurements made on the G6 Antarctic ice core $(100 \mathrm{~m}$ deep) show enhanced growth rates above a depth of $30 \mathrm{~m}$ (Zone 1) and in the interval between 70 and $80 \mathrm{~m}$ (Zone 2). Crystal growth in Zone 1 most probably takes place by a process of sublimation and condensation. The higher growth rate in Zone 2 is most probably related to the pore close-off transformation process in which a non-uniform strain field is created to form air bubbles by plastic deformation and "cannibalization" of individual ice crystals.
\end{abstract}

\section{INTRODUCTION}

The average size of ice crystals increases with time (depth) after deposition on a polar snow field. The in situ growth processes of crystals from various sites have been measured and are discussed in terms of the temperature regime according to

$$
S=S_{0}+k_{0} e^{(-Q / R T)} t,
$$

where $S$ and $S_{0}$ are crystal areas at a specific depth and at the surface, respectively; $T$ is temperature; $t$ is time; $R$ is the gas constant; $k_{0}$ is a constant; and $Q$ is the activation energy (Gow, 1971). Under dry-snow conditions, a typical value for density of near-surface snows is between 0.3 and $0.4 \mathrm{~g} \mathrm{~cm}^{-3}$. Ice grains formed in the upper layers usually settle or pack at a depth of $10-15 \mathrm{~m}$ below the snow surface, and at a a density of about $0.55 \mathrm{~g} \mathrm{~cm}^{-3}$. Below this, the density increases and firn transforms into ice at a depth of 50-120 m and a density of about $0.8 \mathrm{~g} \mathrm{~cm}^{-3}$. This metamorphic change with time and depth is a function of mean annual surface air temperatures, stresses, and specific but sometimes varying snow-structure configurations. This study involves the continuous meausurement of crystal size made on two shallow ice cores from Antarctica. Particular attention was paid to the changes occurring in the structure and to metamorphic properties occurring in the firn/ice column represented by each core.

\section{EXPERIMENTAL METHOD}

One ice core (G6) was recovered at $70^{\circ} \mathrm{S}, 40^{\circ} \mathrm{E}$, by the JARE-27 team in 1986. Continuous crystal-size measurements were made on samples between the $0.5 \mathrm{~m}$ and $100 \mathrm{~m}$ depth. The other ice core (NBY-89) was recovered in 1989 at Byrd Station, $80^{\circ} \mathrm{S}, 120^{\circ} \mathrm{W}$, by a team from the State University of New York (SUNY) at Buffalo. Annual mean temperature at $\mathrm{G} 6$ is $-43^{\circ} \mathrm{C}$; at Byrd Station it is $-28^{\circ} \mathrm{C}$. Accumulation rates at $\mathrm{G} 6$ and Byrd Station are 8.4 and $11 \mathrm{~cm}$ of ice equivalent $\mathrm{a}^{-1}$, respectively.

Each $50 \mathrm{~cm}$ long portion of the $\mathrm{G} 6$ core was microtomed and the surface was sublimated in the cold room at $-20^{\circ} \mathrm{C}$ until crystal boundary grooves appeared (within a few hours). A linear intercept method was used to measure continuous sizes under a microscope. A preliminary test indicated that the mean crystal size of at least 80 crystals provides a representative average value for each depth level (Horita, 1992). Crystal area was calculated on the G6 core by using a conversion constant of 1.5 which is the ratio between a two-dimensional diameter and the length between two crystal boundaries along a vertical measuring line (Fujita, 1992). That is, crystal area $=1.5 \pi(\text { crystal size })^{2} / 4$. Crystal-size measurements on the Byrd core were made by measuring the area of each crystal with a Zeiss Particle Size Counter on a fullscale thin-section micrograph of each thin section measured.

\section{EXPERIMENTAL RESULTS AND DISCUSSIONS}

A total of about 70000 individual crystals was counted from both cores. Grain-size enhancement due to the existence of pore spaces was corrected by using a correction curve obtained as a function of density.

* Kitami Institute of Technology, 165 Koen, Kitami, Hokkaido 090, Japan. 


\section{DEPTH $m$}

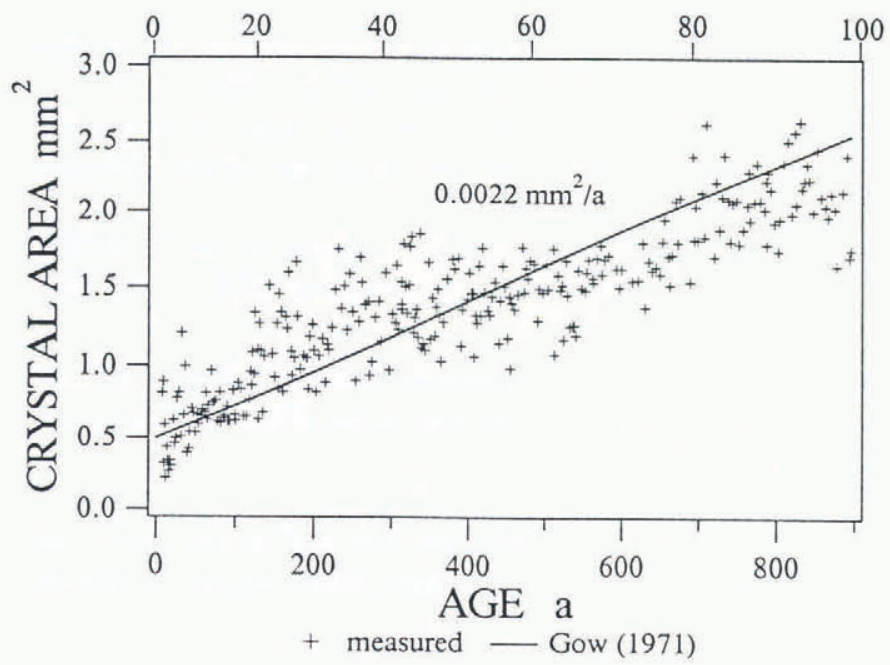

Fig. 1. Crystal area growth curve for location G6, Antarctica.

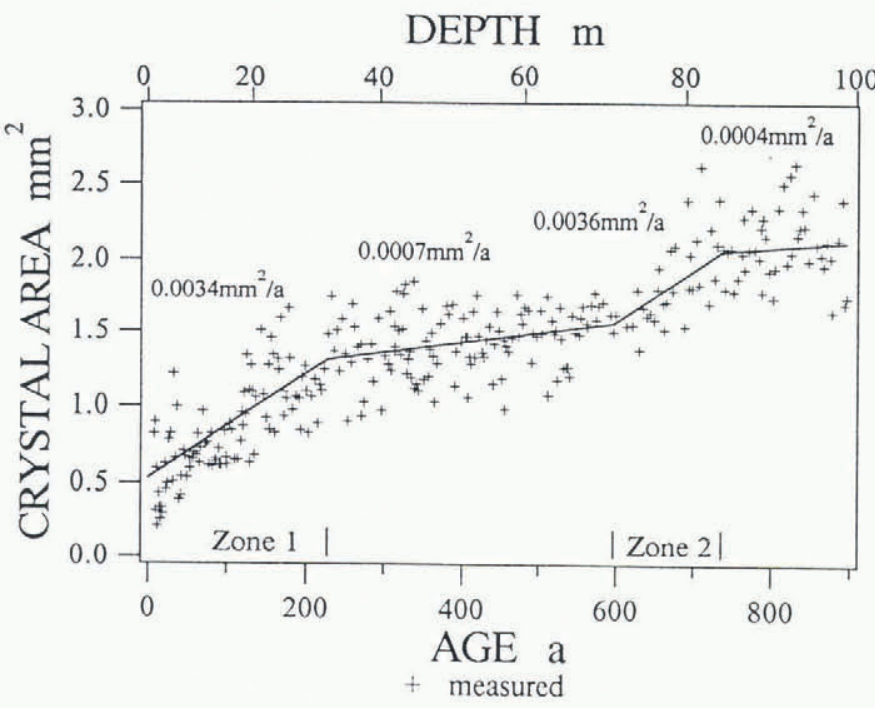

Fig. 2. Crystal area growth rate changes from continuous measurements made on the G6 Antarctic ice core.

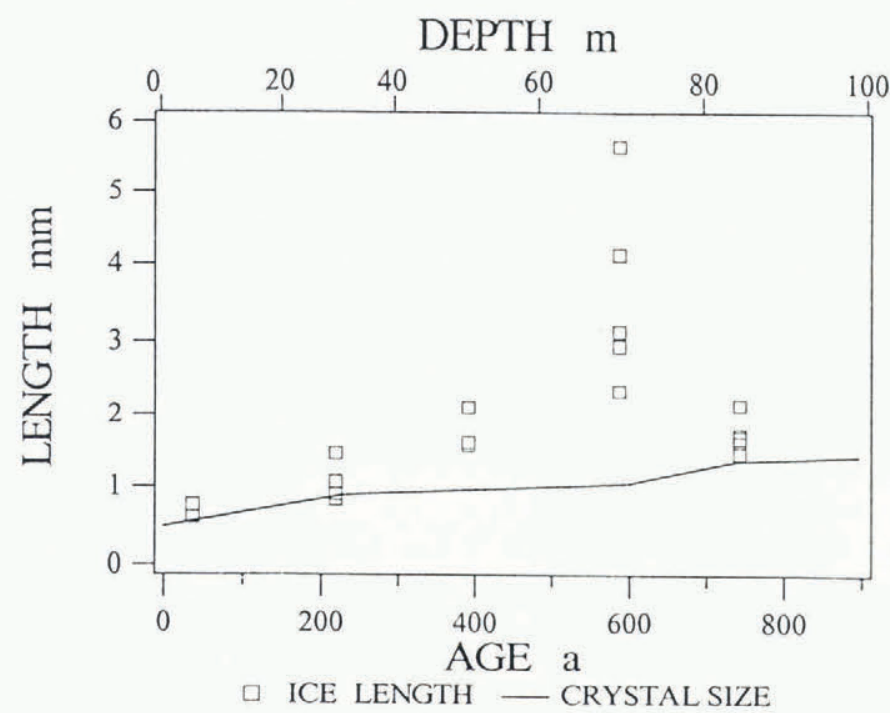

Fig. 3. Crystal area size and length of ice crystals between pores.
An average crystal growth rate, $k_{0} e^{(-Q / R T)}$ for the G6 core is $1.8 \times 10^{-3} \mathrm{~mm}^{2} \mathrm{a}^{-1}$; this is within $10 \%$ of the estimated value of $2.2 \times 10^{-3} \mathrm{~mm}^{2} \mathrm{a}^{-1}$ published by Gow for the deep Byrd ice core (1971). These data are shown in Figure 1. The crystal-size curve in Figure 1 clearly shows two high growth-rate intervals of $3.4 \times$ $10^{-3} \mathrm{~mm}^{2} \mathrm{a}^{-1}$ between the depths of 0.5 and $30 \mathrm{~m}$ (Zone 1), and $3.6 \times 10^{-3} \mathrm{~mm}^{2} \mathrm{a}^{-1}$ between the depths of 70 and $80 \mathrm{~m}$ (Zone 2). These data are shown in Figure 2. Results also show that the average crystal-size length is almost equal to the ice length which is the length of aggregates of crystals between pore spaces along the measuring line in Zone 1 (Fig. 3). This result suggests that crystal growth in Zone 1 is controlled by a decrease in pore space, and further suggests that the higher growth rate observed in Zone 1 is caused by sublimation and condensation of water vapor along pore spaces.

The crystal growth rate measured at Byrd Station (Fig. 4) is $0.0093 \mathrm{~mm}^{2} \mathrm{a}^{-1}$ which is again close to the value (shown as a solid line in Figure 4) published by Gow (1971). Figure 5 shows that the permeability measure-

\section{DEPTH $\mathrm{m}$}

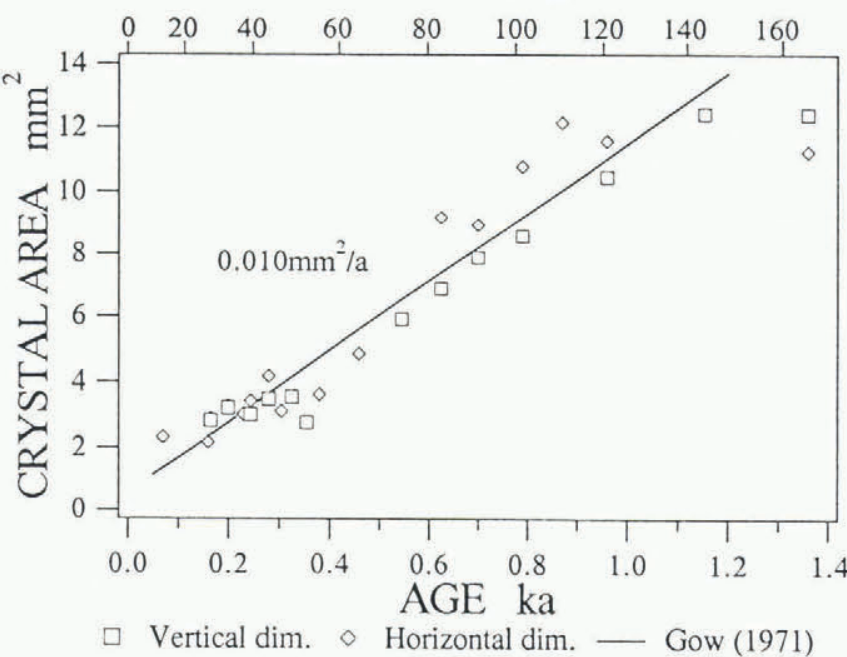

Fig. 4. Crystal area growth curves from the Byrd Station ice core.

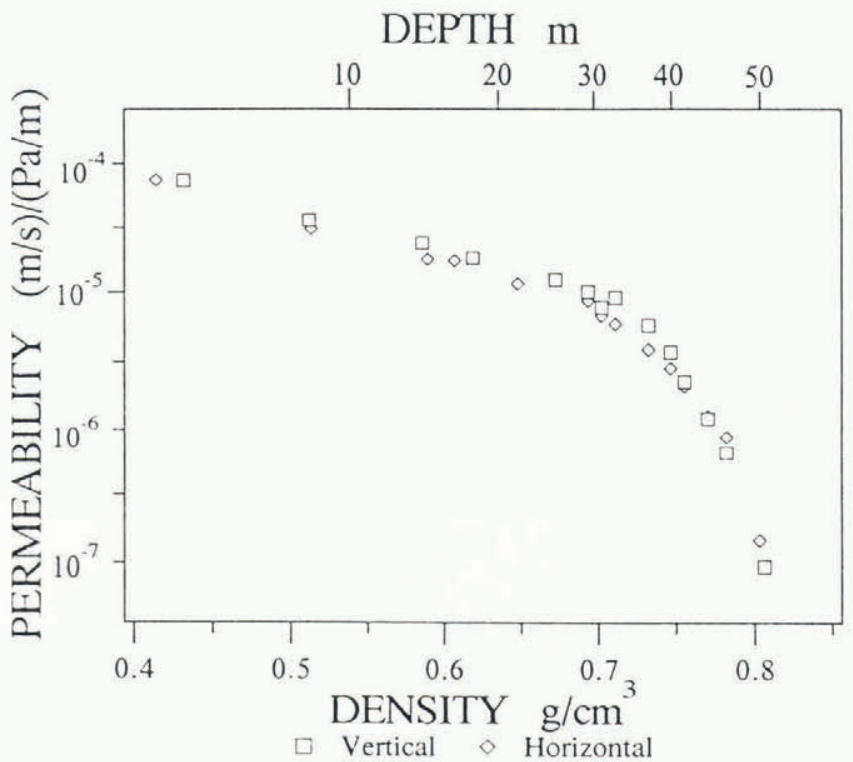

Fig. 5. Measured permeability curve of core samples from Byrd Station, Antarctica. 
ments indicate that a much higher permeability value exists in the firn structure down to a depth of about $30 \mathrm{~m}$, suggesting that a vertical, vapor-flow process is taking place in the pore space. These results also imply that crystal growth in the near-surface firn may take place by a sublimation and condensation mechanism (Colbeck, 1983). Below the depth of Zone 1 (above $30 \mathrm{~m}$ ), grainboundary migration may be responsible for the crystal growth process which tends to minimize the crystalboundary area.

The reason for the higher growth rate in Zone 2 is not yet clear, but this depth interval corresponds to the pore close-off zone at G6. The in situ, non-uniform strain-field would acclerate grain-boundary migration and lower the free energy of the ice crystal, resulting in a higher growth rate.

\section{REFERENCES}

Colbeck, S. C. 1983. Theory of metamorphism of dry snow. 7. Geophys. Res., 88(C9), 5475-5482.

Fujita, M. 1992. Anion concentration and crystal growth rate at G6, Antarctica. (Graduation thesis, Toyama University.)

Gow, A.J. 1971. Depth-time-temperature relationships of ice crystal growth in polar glaciers. CRREL Res. Rep. 300.

Horita, K. 1992. A continuous measurement of crystal size on the G6 Antarctica ice core. (Graduation thesis, Toyama University.)

The accuracy of references in the text and in this list is the responsibility of the authors, to whom queries should be addressed. 